\title{
POLITTICA MIGRATORIA VENEZOLANA, UNA TRADICIÓN DE RECEPCIÓN. EL CASO DE LA INMIGRACIÓN ESPAÑOLA DEL SIGLO XX.
}

\section{VENEZUELAN MIGRATION POLICY, A TRADITION OF RECEPTION. THE CASE OF SPANISH INMIGRATION OF THE TWENTIETH CENTURY.}

\section{Jhonny Castro Trujillo}

Investigador Asociado a la Universidad Técnica de Manabí, Portoviejo, Ecuador jhonnycastro@gmail.com

Resumen: El presente trabajo se realiza un análisis documental de política pública sobre la historia migratoria venezolana desde sus orígenes como república hasta finales del siglo XX, centrando su mirada en los procesos de inmigración europea que se produjeron durante el siglo XX y en especial la inmigración española. Según la estadística fue la más numerosa dentro de los migrantes europeos que llegaron a Venezuela, y por el hecho de Venezuela haber recibido el $52 \%$ de toda la emigración española dirigida a América. Esto con el propósito de constatar que los programas y políticas inmigratorias constituyeron una política de Estado de aproximadamente ciento cincuenta años de experiencias de recepción, acogida e integración de migrantes en Venezuela.

Abstract: The present work is a documentary analysis of public policy on Venezuelan migration history from its origins as a republic until the end of the 20th century, focusing its attention on the European immigration processes that occurred during the 20th century and especially Spanish immigration. According to statistics, it was the most numerous among European migrants who arrived in Venezuela and due to the fact that Venezuela received $52 \%$ of all Spanish emigration to America. This with the purpose of verifying that the immigration programs and policies constituted a State policy of approximately one hundred and fifty years of experiences of reception, reception and integration of migrants in Venezuela. 


\section{l. Introducción}

Existen investigaciones, antecedentes y bibliografía que dan cuenta que en Venezuela, desde el inicio del proceso independentista del reino español, su separación de la Gran Colombia y constitución como República de Venezuela, realizó acciones para incentivar procesos inmigratorios, como políticas de Estado, fundamentalmente de Europa, como una manera de contrarrestar diversas carencias en el orden económico, agrícola y poblacional que dejo la larga guerra de independencia, condiciones a las que se afrontaba una nueva república independiente. No obstante, estas iniciativas inmigratorias trascendieron ampliamente la etapa de los primeros años de vida independiente de Venezuela, manteniéndose e incrementándose en forma de políticas por varias décadas.

Este proceso de inmigración no fue lineal, por el contrario, puede ser visto como un conjunto de políticas públicas, que tienen en común el asentamiento de personas provenientes de otros países. Desde la perspectiva gubernamental, se buscaba el progreso y desarrollo de la nación, desde el lado de los migrantes, era una segunda oportunidad de rehacer su vida y encontrar las condiciones que sus países de orígenes no le podían ofrecer.

Este proceso migratorio masivo que se produjo en Venezuela a lo largo de todo el siglo XX tiene como contextos varios hechos históricos que sirvieron de impulso o condicionante para que el mismo se realizara en la magnitud y forma como sucedió. En primer lugar, la primera Guerra Mundial que generó graves consecuencias a la economía europea y mundial ${ }^{1}$. Posteriormen-

1. Posteriormente a la I Guerra Mundial, la economía mundial se resintió con el denomi- te, en segundo lugar, el inicio de la guerra civil española, el estallido de la segunda Guerra Mundial y la dictadura del General Francisco Franco en España. Las pérdidas humanas, económicas y de la capacidad productiva en general de Europa y la persecución política de judíos durante el período nazi, o de republicanos e intelectuales por parte del régimen franquista, generaron condiciones propicias para la emigración de ciudadanos de un sin número de países de Europa, en especial los de la periferia. En tercer lugar, la estabilidad económica y política de Venezuela extendida por décadas, inclusive en el período entre guerras, pues la expansión de su economía, el boom de los precios del petróleo y los ingresos adicionales fruto de la negociación de regalías con las empresas trasnacionales, convirtieron a Venezuela en un país atractivo para la inmigración.

A estos tres hitos de corte histórico contextual se le suma en efecto bisagra, una tradición de apertura migratoria que se venía desarrollando, en distintas magnitudes, desde 1830. Con lo cual la confluencia con estos hechos históricos señalados ocurre luego de más de 70 años de experiencia de recepción, acogida e integración de migrantes en Venezuela.

El presente artículo realiza una revisión, desde el análisis de las políticas públicas, en la historia migratoria venezolana, centrando su mirada en los procesos de inmigración europea que se produjeron en el siglo XX y en especial la inmigración española, la cual según la estadística fue la más numerosa dentro de los migrantes europeos que llegaron a Venezuela ${ }^{2}$, y por

nado Crack o recesión del año 1929 en Estado Unidos.

2. Según el autor español Julio Hernández Borge en "Factores de atracción de los países de desti- 
el hecho de Venezuela haber recibido el $52 \%$ de toda la emigración española dirigida a América ${ }^{3}$. Esto con el propósito de evidenciar que los programas y políticas inmigratorias constituyeron una política de Estado sostenida en el tiempo por aproximadamente ciento cincuenta años.

Para ello se toman en cuenta las distintas legislaciones aprobadas, la institucionalidad creada, el perfil migratorio definido en cada etapa, así como la asignación de recursos. Lo que además da cuenta de la centralidad del Estado como actor fundamental en la construcción de una nueva sociedad durante las primeras décadas de vida republicana.

Todo este proceso histórico migratorio de más de siglo y medio en Venezuela, fue en un primer momento exclusivamente europeo, luego compuesto por naciones asiáticas, del medio oriente, posteriormente nuevamente europeo y más recientemente de contingentes de América Latina y el Caribe, produjo un alto impacto social, económico y cultural que da forma a la sociedad, descrita en la Constitución Nacional del año 1999, como "multiétnica y pluricultural".

Así el artículo está divido en cinco grandes etapas, agrupadas por los principales bloques históricos, a modo de marco referencial. En todas se busca identificar y reseñar las distintas iniciativas que en materia inmigratoria se pusieron en ejecución por los distintos gobiernos de la épo-

no" de acuerdo a estadísticas oficiales de España, ver la obra: Un lugar donde vivir y crear. Españoles en la Venezuela contemporánea (pág. 19).

3. Según el autor español Julio Hernández Borge en "Factores de atracción de los países de destino" de acuerdo a estadísticas oficiales de España, ver la obra: Un lugar donde vivir y crear. Españoles en la Venezuela contemporánea (pág. 19). ca, teniendo siempre como contexto la realidad internacional de cada momento. La primera etapa, época colonial y gran colombiana, que va desde 1800 a 1830 . La segunda etapa denominada, Republicana, abarca los años 1830 y 1900. La tercera etapa, Pausa Gomecista, refleja el periodo entre 1900 y 1936. La cuarta etapa, Periodo Post Gomecista, da cuenta de los años 1936 a 1948. Finalmente la quinta y última etapa, La Política de Puertas Abiertas, se centra en los años de 1948 a 1963.

Finalmente, se mencionan las migraciones latinoamericanas hacia Venezuela que se intensificaron a partir de los años 70 y que continuaron hasta finales del siglo XX.

\section{Breves rasgos de la época colonial y de la Gran Colombiana.}

Durante la etapa colonial, el poblamiento e intercambio económico-comercial de la Capitanía General de Venezuela se daba mediante la llegada de españoles y canarios principalmente, también con alemanes e ingleses. Según estimaciones de geógrafo y naturalista Alejandro de Humboldt para inicios del siglo XIX la población del territorio venezolano era de 800.000 habitantes, de los cuales 12.000 eran españoles o canarios, lo cual para ese momento representaba que el 1,5\% de la población era foránea y había migrado en algún momento a Venezuela.

En pleno proceso de búsqueda de su independencia política del Reino español, Venezuela marcaba la ruta de lo que sería posteriormente su tradición con respecto al tema de extranjeros haciendo vida en 
su territorio. Así el 1 de julio de 1811 se firmaba la "Declaración de los Pueblos" y en la sección referida a los Derechos del Hombre en Sociedad se señalaba “... se abrían las puertas para el ingreso de extranjeros en el país, garantizándoseles derechos para su establecimiento definitivo al plantearse en los artículos 25, 26 y 27 que todos los extranjeros de cualquier nación serían recibidos en la provincia de Caracas; que las personas y propiedades de los extranjeros gozarían de la misma seguridad que la de los demás ciudadanos con tal de que reconocieran «la soberanía e independencia y respeten la religión católica única en el país», y que aquellos extranjeros que residieran en la provincia de Caracas, habiéndoles naturalizado y siendo propietarios, gozarían de todos los derechos de los ciudadanos" (Rey 2011, págs.: 25 y 26). Estos preceptos también fueron contenidos en la Constitución Federal sancionada en diciembre del 1811.

Posteriormente en el año 1813, el propio Simón Bolívar realizaba la siguiente invitación "suspended a lo menos el juicio; y si por vosotros mismos buscáis la verdad, Caracas no solo ha convidado, sino que desea ver entrar por sus puertos a todos los hombres útiles que vengan a buscar un asilo entre nosotros, y ayudarnos con su industria y conocimientos, sin inquirir cual sea la parte del mundo que les haya dado la vida" (Rey, 2001: 26).

Tanto el texto de 1811 como el de 1813 evidencian que las motivaciones que en esta etapa de pre independencia se tenía para con los extranjeros, se basaba en el reconocimiento de la naciente república, como independiente y soberana completamente ajena del reino español.

Una vez alcanzada la independencia en el año 1821 y bajo la figura de la Gran
Colombia 4 , comenzaron a llegar personas provenientes de Alemania, Inglaterra, Francia Italia y Norteamérica como funcionarios consulares, comerciantes y algunos aventureros. Es durante este período que se inicia lo que a la postre sería la política de las "colonias", con la llamada Colonia El Topo de Tacagua.

Las Colonias, que se iniciaron a partir de la década de 1820, no eran más que asentamientos de extranjeros (colonos): ingleses, escoceses o habitantes de Madeira o de las Islas Canarias, quienes se trasladaban con sus familias, y en donde el gobierno concedía tierras baldías para el trabajo agrícola y la cría de ganado.

\subsection{Etapa Republicana: 1830- 1908}

Tras la separación de la Gran Colombia, el 13 de junio de 1831 bajo la presidencia de José Antonio Páez, se promulgaron las primeras normas destinadas a autorizar al poder Ejecutivo a promover la inmigración de ciudadanos canarios $^{5}$, con el objetivo de poblar el territorio nacional ante las

4. La Gran Colombia es la república surgida inmediatamente después de alcanzar el proceso de independencia del Reino Español, estaba conformada por los virreinatos de Venezuela, Nueva Granada, Quito, Guayaquil su vigencia fue de 1819 a 1830.

5. Entre las razones para estimular la inmigración de los ciudadanos de Canarias se consideraba que contaban "con mayores ventajas y mejores seguridades y buen éxito podían satisfacer los deseos y exigencias de los hacendados. Ellos además de ser de la misma religión, hablar el mismo idioma y compartir muchas de las costumbres con los criollos, vivían en el archipiélago una situación de miseria generalizada que los impulsaba continuamente a trasladarse a América para convertirse en jornaleros" (Rey, 2011: 37). 
vastas extensiones de suelo. Posteriormente estas autorizaciones se extendieron a las demás naciones europeas. En dicho decreto se contemplaba la "carta de naturalización a todos aquellos inmigrantes canarios que tan pronto pisaran el territorio nacional; se les exoneraría del servicio militar o de cualquier otra contribución directa por un período de diez años, y a cada padre de familia se le concedería una extensión de tierras baldías para su cultivo" (Rey, 2011: 38).

En abril de 1832, menos de un año después, se emitió otro decreto ya no solo a los habitantes provenientes de las Islas Canarias, sino que permitía la importación de productos de España así como el establecimiento de españoles en el país ${ }^{6}$. Como consecuencia de estas políticas el flujo migratorio iba en ascenso, Margolies citado por Rey 2011, señala que entre los año 1831 y 1833 ingresarían al país más de 10.000 migrantes, de los cuales al menos 8.000 serían de las Islas Canarias (Rey, 2011: 38).

En 1837 el Congreso aprobó una nueva normativa de protección de inmigrantes de otros países, con este nuevo instrumento se autorizaba a empresarios particulares a traer trabajadores de Europa, "...por los que el gobierno pagaría 30 pesos, además de concederles «carta de naturaleza» tan pronto como llegaran a un puerto vene-

6. No es un detalle menor que en 1832 apenas dos años después de la desintegración de la Gran Colombia, Venezuela aprobara leyes que permitieran el establecimiento de españoles en el país. Reino con el que disputo a sangre y fuego su independencia política y que fue reconocida oficialmente por parte de España el 30 de marzo de 1845 . Es decir aun sin tener legal y políticamente todos los asuntos zanjados (militarmente sí) se decidió el establecimiento de españoles en Venezuela. zolano y de asignarles tierras baldías para cultivos" (Rey, 2011: 40).

En el mes de mayo de 1840, se promulga un nuevo instrumento legal que ampliaba las facultades y atribuciones del Ejecutivo en materia de fomento a la inmigración, entre las que se destaca: autorizar al poder Ejecutivo para que estimule, promueva y proteja las empresas de inmigración de europeos y canarios para el fomento de la agricultura. El politólogo Juan Carlos Rey destaca que esta modificación legislativa generaba dos tipos de migración, una " $m i$ gración suelta", que continuaba el modelo de los primeros contingentes canarios destinados al servicio de particulares, y, la "colonización particular" realizada por medio de empresas colonizadoras orientadas al cultivo de áreas baldías. Esta segunda modalidad no era más que la ya ensayada política de colonias que se venía realizando desde la etapa de la Gran Colombia.

Como parte del mecanismo de la "migración suelta" solamente en los primeros ocho meses de 1842, según Emilia Troconis ${ }^{7}$, arribaron a puertos venezolanos 997 canarios, 44 franceses, 27 capuchinos catalanes, 19 alemanes, 03 portugueses, 03 prusianos, 1 capuchino no navarro y 1 cura catalán.

En 1843 comenzó la iniciativa de la Colonia Tovar, impulsada por Agustín Codazzi ${ }^{8}$, que a la postre sería uno de los proyectos más emblemáticos. Consistía en el asen-

7. Ver: El Proceso de Inmigración en Venezuela. 1986

8. Ingeniero militar italiano de ocupación artillero, geógrafo y cartógrafo, Finalizada la lucha por la Independencia, dejaría de lado su actividad bélica para dedicarse a lo que realmente le apasionaba, la investigación geográfica y cartográfica, y llevaría a cabo su singular obra: la geografía y el atlas de las provincias venezolana 
tamiento de más de 300 colones alemanes proporcionándoles tierras y casas. Para este proyecto se asignó inicialmente un empréstito de 15.0000 pesos pudiendo llegar hasta 60.000pesos.

Para 1850 con apenas 20 años de vida republicana, Venezuela establece en Europa agencias consulares destinadas a promover y estimular la emigración para el fomento de la agricultura, esto mediante de un Decreto elaborado por el Congreso de la República. Ya desde 1845 cuando se realiza una nueva reforma a la Ley de Inmigración y a la Ley sobre Sociedades de Inmigración, el gobierno de entonces tomó la iniciativa de imprimir ejemplares de ambas leyes en inglés francés y alemán y enviarlas a los consulados de Venezuela en Liverpool, Belfast, Talmouth, Bremen, Hamburgo, Bruselas, Burdeos, Le Havre y París. El rol que desempañaron estos consulados como fuentes de información fue determinante en las sucesivas oleadas de migración europea hacía Venezuela.

Al respecto considero importante citar dos fragmentos de una carta dirigida en 1847 al Cónsul en Londres, Jaime Milligan por la Sociedad de Inmigración tropical donde se señala:

“(...) Los motivos que se han tenido para elegir a Venezuela son en parte la fertilidad de su suelo, pero principalmente la liberalidad de sus leyes de inmigración (...) hemos sabido de que el Gobierno de Venezuela concede a los emigrados: libertad perfecta de religión, industria comercial sin trabas, tierras sin otro costo que el de mensuras, y exención de todo impuesto y servicio militar por 15 años."(Rey, 2011: 58 y 59).

Durante el resto del siglo XIX se continuaron emitiendo resoluciones, decretos, leyes referentes a la inmigración y colonización, que se iban ajustando o adaptando de acuerdo al contexto nacional. En ese sentido, destaca en el año 1855, las modificaciones que se realizan a la Ley de Inmigración con el objeto de permitir y estimular la migración asiático a territorio venezolano.

Otro pico migratorio se registró posterior a la culminación de la Guerra Federal ${ }^{9}$ en el año de 1864, debido a la pacificación del territorio nacional y la relativa estabilidad política que comenzaba a gestarse. Así fundamentalmente llegaron a Venezuela españoles, italianos, alemanes, franceses y corsos para dedicarse al comercio, la agricultura y la ganadería.

Una vez más, como en otros momentos, la llegada de inmigrantes a Venezuela estuvo marcada por la conjunción de dos hechos importantes, no solo la flexibilidad migratoria o políticas de fomento en el ámbito migratorio que ponían en práctica los distintos gobiernos, sino también fuertes conflictos de orden político, social y económico en alguna región del mundo. Así en esta etapa destaca la llegada de italianos por el inicio del conflicto con respecto a la unificación italiana "...desde Italia varias familias pudientes llegaron a liquidar todos su bienes para viajar, con sus propios barcos, y establecerse en los Andes venezolanos. El incremento de esta población sería tan significativo ${ }^{10}$ que tra-

9. Después de la Guerra de Independencia, represento la más larga contienda civil en el territorio nacional; y fue, para Venezuela, una prolongación de la Guerra de Independencia, en cuanto a los problemas de carácter social y político dejados sin resolver una vez lograda definitivamente la emancipación de España con las victorias de 1821 y 1823 y la separación de la Gran Colombia bolivariana en 1830 .

10. Aunque existen antecedentes previos al año 1850 de presencia de familias italianos en Venezuela, y que ambos países habían suscrito el 
jo como consecuencia la creación de un Consulado del Reino de Italia en la Guaira y una oficina consular en Maracaibo" (Rey, 2011: 71 y 72).

De la misma manera el conflicto entre España y Marruecos promovió la inmigración de judíos sefarditas y la afectación que tuvo el Líbano por la expansión del Imperio Otomano produjo que los primeros migrantes libaneses arribaran a Venezuela en 1882. En 1884 se realizaron ampliaciones a la Ley de Inmigraciones para permitir el ingreso de personas procedentes de China e India.

En el cierre del siglo XIX, durante la presidencia de Antonio Guzmán Blanco ${ }^{11}$, se dio un fuerte impulso al fomento de la inmigración, creando institucionalidad (Dirección General de Inmigrantes y Junta Central, Juntas subalternas y agencias en el exterior) y normativas al respecto, destinando más recursos públicos, lo que produjo rápidos resultados y estableciendo un modelo de gestión migratoria más ordenado. "La política migratoria guzmancista además de manejar la idea de una migración ordenada, dirigida por el Estado, para ser integrada en las empresas agrícolas particulares, suponía una segunda vertiente conformada por la creación de colonias agrícolas mixtas, donde, a diferencia de los proyectos previos, se asentaron de manera conjunta extranjeros y venezolanos con el fin de impulsar la integración social, económica y étnica" (Rey, 2011: 74).

Tratado de Amistad, Comercio y Navegación en 1861; es con la reunificación italiana en 1870 cuando realmente comienza la inmigración italiana a Venezuela. Ver: El Proceso de la Inmigración Venezolana de Ermila Troconis.

11. Fue Presidente de Venezuela en tres ocasiones 1870-1877, 1879-1884, y 1886-1888.
Esta práctica de constituir proyectos agrícolas (base del proceso migratorio de ese momento) de carácter mixto entre venezolanos e inmigrantes, buscaba la adaptación de estos últimos a las tierras, costumbres y culturas de Venezuela. Pero a la vez, represento una forma de evitar la conformación de zonas excluidas basadas en habitantes de una misma nacionalidad.

El Censo de población del año 1891 reseñaba un total de 42.898 habitantes extranjeros en Venezuela, de ese total personas provenientes de España eran 13.223.

\subsection{Pausa Gomecista 1908-1935}

Al iniciar el siglo XX, el Censo Nacional que correspondía realizarse en 1900 no se hizo, por lo que los datos de los primeros años del siglo XX se generaban en función de las estimaciones y proyecciones del último Censo realizado, el de 1891. Según dichas estimaciones para 1900 la población total de Venezuela se encontraba alrededor de 2,3 millones de personas, siendo que la población extranjera no llegaba al $2 \%$ para ese momento.

Aunque esta cifra parece no tener mucho peso cuantitativo, Rey (2011) refiere la importancia que desde el punto de vista cualitativo representa, por su aporte en el desarrollo económico en esta etapa. Cabe destacar, que el perfil del inmigrante para ese momento era el de personas que habían venido de manera independiente, o a través de algunas de las iniciativas gubernamentales, para dedicarse a actividades económicas-productivas como el sector agrícola, minero, servicios y el comercio.

En 1903, bajo la presidencia de Cipriano Castro, se promulgó la Ley de Extranjeros, la cual tuvo como contexto el bloqueo de 
los puertos venezolanos ocurrido en diciembre de 1902,12 "De esta manera dio un marco legal rígido a aquella política inmigratoria dual, donde la inmigración selectiva impulsada por el Estado seguiría normada por la Ley de Inmigración y Colonización, mientras que la inmigración espontánea quedo regida por la nueva ley" Rey (2011: 85)

Todo este marco sirvió de antesala para lo que fueron los veintisiete años de gobierno dictatorial del General Juan Vicente Gómez $^{13}$, el cual se caracterizó por un notable descenso en el proceso inmigratorio, "...Gómez desconfiaba mucho de las ideas políticas que pudieran traer los extranjeros al país, por lo que nunca lograron desarrollarse proyectos de gran escala" Rey (2011:86). Como parte del control político y territorial de un gobierno dictatorial y con los antecedentes del bloqueo de los puertos impuesto en el año 1902, el gobierno de Gómez era receloso y precavido sobre a quien deja ingresar, en ese sentido, "varios documentos oficiales ofrecen referencias sobre la necesidad de escoger cuidadosamente a los extranjeros que entraran al país, no solo para evitar «holgazanes» $y$ «aventureros» sino fundamentalmente a anarquistas y comunistas" (Rey, 2011: 86).

En 1912 el Congreso promulgó una nueva Ley de Inmigración y Colonización, que buscaba recuperar las iniciativas de las

12. Durante el gobierno de Cipriano Castro, el gobierno vio mermados sus ingresos fiscales por lo que tuvo en 1902 que suspender los pagos y amortizaciones de la deuda externa pública que se tenía con Inglaterra y Alemania, lo que trajo como consecuencia el bloqueo de los principales puertos venezolanos por fuerzas navales de estos países. Este conflicto culmino con la firma de los Protocolos de Washington de 1903.

13. Presidente de Venezuela entre 1908 y 1935. llamadas Juntas que impulsaran la inmigración al país. Así existen referencias sobre proyectos inmigratorios de familias alemanas vinculados a las consecuencias generadas por la primera guerra mundial o de habitantes de Anatolia quienes huían de la expansión turca.

No obstante, la situación de la inmigración promovida por el Estado en este periodo cambio fundamentalmente con el descubrimiento del petróleo en Venezuela y el desarrollo de la actividad petrolera. Aunque desde finales del siglo XIX se conocía de la existencia de petróleo en Venezuela, fue entre los años 1914 a 1917 que fueron descubiertos nuevos yacimientos petroleros en el occidente, lo cual acentuó la entrega de concesiones, la instalación de empresas petroleras foráneas y el desarrollo de la industria ${ }^{14}$. Fue precisamente en 1917 cuando inicia operaciones la primera refinería venezolana, la refinería de San Lorenzo. "Con la llegada de las compañías petroleras, además de la llegada de técnicos y gerentes extranjeros, vendría una gran oleada de obreros y trabajadores desde las Islas del Caribe directamente a las zonas petroleras, donde además de involucrarse en actividades directamente relacionadas con la extracción, participarían en el desarroIlo de áreas de servicios" (Rey ,2011: 90).

14. Para comprender la magnitud del desarrollo de la industria petrolera y su impacto en la economía venezolana de aquellos años, de lo que se conoce como el "primer boom" después de veinte años de actividad, Venezuela se había convertido en el mayor exportador de petróleo del mundo y el segundo mayor productor de petróleo, después de Estados Unidos. La exportación de petróleo se disparó de $1,9 \%$ a $91,2 \%$ entre 1920 y 1935 , Ver Franklin Tugwell (1975). The Politics of Oil in Venezuela. Stanford University Press 


\subsection{Período Post Gomecista 1936-1948}

Como parte de las transformaciones políticas que inician con la muerte de Gómez, comienza un proceso de reforma general del Estado y la construcción de una nueva administración pública, orientado a fortalecer las capacidades estatales en áreas como la salud, educación y la agricultura, todo esto enmarcado en el llamado Programa de Febrero ${ }^{15}$.

Dentro del Programa de Febrero, había un apartado exclusivo para el tema de inmigración, el cual estaba orientado a incentivar la inmigración, en especial la de europeos, esto sustentado en los planteamientos de Alberto Adriani16, para fundar colonias agrícolas a lo largo del territorio nacional. Es esta es la etapa que puede denominarse de la de inmigración selectiva.

En el año 1936 se aprueba la Ley de Inmigración y Colonización, y se creó la Oficina de Inmigración y Colonización adscrita al Ministerio de Agricultura y Cría. Se

15. Este fue el plan de gobierno impulsado por el general Eleazar López Contreras, quien se había desempeñado como Ministro de Guerra y Marina de Juan Vicente Gómez y quien fue electo Presidente de la República por el gabinete ministerial luego del fallecimiento de Gómez. Este plan contemplaba los siguientes ocho puntos: régimen de legalidad; higiene pública y asistencia social; vías de comunicación; educación nacional; agricultura y cría; política fiscal y comercial; inmigración y colonización; puntos complementarios.

16. Economista, escritor y político venezolano que fue Ministro de Agricultura y Cría del gobierno de Eleazar López Contreras. Hijo de inmigrantes italianos radicados en Venezuela, que junto con otros pensadores de la época como Arturo Uslar Pietri era partidario del "mejoramiento de la raza" a través de su blanqueamiento por medio de las inmigraciones. modifica la concepción restrictiva de la migración y comienza una política migratoria gradual y controlada cuyo principal objetivo era contribuir a la agricultura. Se establece el perfil del inmigrante, preferentemente agricultor, que favorezcan el desarrollo agrícola a través de colonias. También el ingreso de inmigrantes con oficios reconocidos como artesanos industriales y mecánicos que puedan contribuir al desarrollo de otras actividades productivas. Todo esto en el marco de un plan general de política o plan nacional de desarrollo -si cabe el término para la época- como era el Programa de Febrero.

Este contexto interno venezolano coincide con el contexto internacional, específicamente en España de la Guerra Civil (1936-1939) fruto del golpe de Estado contra el gobierno de la segunda república, con lo cual empezaron a llegar grandes cantidades de refugiados y exiliados políticos. Situación que se mantuvo con la instauración de la dictadura de Francisco Franco a partir de 1939.

En el año 1937, se crea la Ley de Extranjeros, donde se establecen los derechos y deberes de los que quisieran residir en Venezuela. Cabe destacar que, en esa ley se establecieron restricciones de orden político para grupos o ideas que pudieran ir en contra del gobierno constituido de Venezuela, en especial las ideas de orden comunistas prohibidas en la Constitución de 1928, texto de la época gomecista que seguía vigente, pudiendo ser catalogados de traidores a la patria e incluso ir a prisión ${ }^{17}$. Esta ley tuvo como

17. Como hecho emblemático de esta política en el año 1937 el Presidente López Contreras expulso del país a los dirigentes del Partido Democrático Nacional (PDN), en función de lo estipulado en el inciso sexto del artículo 32 de la Constitu- 
contexto doméstico la intensa actividad de los partidos políticos y las demandas de democratización en Venezuela que, tras una larga dictadura militar buscaba la construcción de la democracia política a través del llamado a unas elecciones generales, la legalización de los partidos y sindicatos, reforma agraria entre otras.

Es así que en 1937 se creó la Dirección Nacional de Seguridad y Extranjeros "como un organismo de control y, junto con las leyes de actividad de extranjeros del 7 de agosto de 1939 y 29 de junio de 1942, se fueron levantado murallas de contención debido al temor que causaba la penetración de ideas políticas extrañas «ya no solamente el comunismo sino también el nacionalsocialismo» en el contexto de la segunda guerra mundial" (Rey, 2011:95).

En el año 1938 se crea el Instituto Técnico de Inmigración y Colonización (ITIC), adscrito igualmente al Ministerio de Agricultura y Cría, el ITIC estaría encargado de coordinar y supervisar el proceso migratorio en el país, así como de hacer un registro de los extranjeros en el país. Fue este instituto el que terminó de delinear cuales serían los inmigrantes "deseables" o "indeseables" para el país. Dentro de los inmigrantes "deseables" se encontraban agricultores, obreros y artesanos; mientras que los "indeseables" 18 la lista

ción de 1928 prohibía todo tipo de actividad y propaganda comunista. El PDN fue una plataforma política creada en 1936 Este frente único de izquierdas nació en el Estado Zulia y entre sus integrantes figuraban Valmore Rodríguez Jóvito Villalba y Rómulo Betancourt.

18. Es importante destacar que en el año 1938 se suscribió un acuerdo entre el gobierno provisional del País Vasco, presidido por José Antonio Aguirre del Partido Nacionalista Vasco y el go- era más amplia encontrándose a gitanos, buhoneros, comerciantes, periodistas, escritores, artistas, abogados, procuradores empleados de oficina, ministros de cultos, telegrafistas, personas sin oficios determinados, etc. (Rey, 2011). Posteriormente en 1940 fue aprobada una nueva Ley de Naturalización que pasó a derogar la de 1928.

Los principales lugares de Europa de los cuales provenían migrantes en este período de pleno apogeo de la II Guerra Mundial se encuentran portugueses provenientes de las islas de Madeira y Azores, españoles peninsulares, canarios, así como de países de Europa Oriental. En el caso de los canarios, cuyo flujo migratorio fue permanente hacia Venezuela desde la propia época de la independencia, había tomado un nuevo aire, no solo por las nuevas políticas de inmigración adoptadas, sino también por dos elementos externos: a) la pérdida de atractivo de Cuba como destino de migración canaria por la caída de los precios del azúcar que impactó en la actividad agrícola, y b) el fin del Régimen de Puertos Francos en las Islas Canarias adoptado al terminar la Guerra Civil española, lo cual impactó en la economía canaria. Según Berglund citado por Rey (2011), más de 62 veleros partieron en esos años de manera clandestina desde el archipiélago canario hacia Venezuela representando más de 4.100 españoles que ingresaron por esta vía.

A diferencia de los migrantes isleños, cuyas motivaciones principales para migrar estaba lo laboral y económico, en el caso de los españoles peninsulares o de

bierno de Pte. López Contreras. Entre las exigencias del gobierno venezolano estaba que preferiblemente los ciudadanos vascos fueran católicos, esto en el marco de las políticas anticomunistas. 
nacionales de países de Europa del este, la motivación fue más de corte política. Según cifras del ITIC para el año 1939, había aproximadamente 400 refugiados vascos con el apoyo de la congregación de los jesuitas, así como la llegada ilegal de numerosos emigrantes provenientes de las Islas Canarias.

A pesar de que el flujo marítimo descendió durante el desarrollo de la II Guerra Mundial, "la inmigración espontanea se incrementó en 38\% entre 1939 y 1940 y la inmigración "dirigida" registro un aumento del $61 \%$ en esos mismos años. Entre los recién llegados en 1940, el 34\% estaba compuesto por agricultores, el $24 \%$ por profesionales liberales y el $42 \%$ por obreros especializados" datos del Ministerio de Agricultura y Cría citados por Banko (2019:127)

En el año 1945 ocurre un hecho importante de destacar, y es una vez finalizada la II Guerra Mundial se generaban nuevos retos para los países receptores para abordar nuevos éxodos provenientes de Europa. Con la culminación de la segunda guerra mundial y el aumento de tensiones por el inicio de la guerra fría, aumento considerablemente el flujo de emigrantes y refugiados europeos auxiliados por la Organización Internacional de Refugiados (OIR) y la Comisión Intergubernamental para las Migraciones Europeas (CIME) Quintero (2017: 15). Por lo que ese mismo año Caracas sirvió de anfitriona de la Tercera Conferencia Interamericana sobre Agricultura, entre los temas a abordar estaba los de inmigración y colonización.

Venezuela participó con el trabajo realizado por el Ingeniero Roberto Álamo Ibarra, en donde se evaluaba la experiencia adquirida por Venezuela en los siete años de funcionamiento del ITIC para ese mo- mento, lo cual permitió elaborar un plan detallado donde se contemplaran factores que garantizaran el éxito en las colonias agrícolas, eje vertebral de la política inmigratoria. La importancia de este hecho radica en que este encuentro permitió hacer un intercambio y valoración de políticas públicas inmigratorias con fuerte componente agrario entre países de la región en donde Venezuela mostraba una experiencia práctica mucho antes de la conformación de organismos multilaterales especializados en el área como es el Caso de la Organización Internacional de Migraciones (OIM) creada en 1951 o del Alto Comisionado de las Naciones Unidas para Los Refugiados (ACNUR) en 1950.

Posteriormente ingresa en Venezuela un importante número de ciudadanos de naciones europeos al concluir en 1945 la segunda guerra mundial y en años posteriores. La característica de estos emigrados era la búsqueda de mejores condiciones económicas y de vida en vista de la aguda crisis económica de Europa en la posguerra. Según datos de la ONU entre los años 1946 -1959 salieron de Europa alrededor de 7 millones y medio de emigrantes de los cuales dos millones se dirigieron a América Latina (Quintero, 2017: 15).

Para fortalecer la capacidad del ITIC el gobierno de la Junta Revolucionaria ${ }^{19}$ trasfirió la propiedad de un conjunto de tierras con la finalidad de estimular la coIonización. A principios del año 1945 arribó un grupo de inmigrantes yugoeslavos

19. Fue la Junta de Gobierno que se conformó después del Golpe de Estado de 1945. Este período también es conocido como el trienio adeco por el protagonismo del partido Acción Democrática. Es durante este lapso que se convoca a una Asamblea Constituyente se redacta un nuevo texto constitucional y se realizan las primeras elecciones presidenciales universales, directas y secretas. 
a Venezuela, los cuales fueron ubicados en la Colonia Ortiz en el estado Guárico. También era común la llegada de técnicos italianos especializados en temas agropecuarios para realizar experimentos de cruce y mejoramiento de ganado.

La investigadora Ermila Troconis refiere que el gobierno de entonces se esforzaba en demostrar el interés de Venezuela por los refugiados, "...en febrero de ese mismo año de 1948, seis jóvenes españoles, que dijeron ser refugiados políticos, fueron detenidos en Oregón (Estado Unidos), con el fin de ser deportados a España. El Cónsul de Venezuela en Portland, una vez realizadas las averiguaciones de rigor, notifico al gobierno de los Estados Unidos que Venezuela les daría las visas necesarias para su inmediata salida a Venezuela. La noticia apareció en El Nacional de fecha de 25 de febrero bajo el título "Venezuela salva 6 refugiados españoles" (1986: 258).

Es de destacar que, la amplia política inmigratoria basada en colonias agrícolas contaba con buena receptividad no solo a nivel gubernamental sino del pueblo venezolano, lo cual en sí mismo dotaba de legitimidad a esta política, por la interpretación positiva que se hacía de los beneficios de la inmigración para los pueblos y ciudades: "Es curioso observar a través de la prensa de la época, que desde los más lejanos confines de la patria surgen voces solicitando ayuda para llevar inmigrantes a sus pueblos, campos y ciudades, pues ven en ello el único medio de progreso para sus comunidades. Ya no se trata solo de una política gubernamental, sino de un clamor popular" (Troconis, 1986: 261).

La Junta Revolucionaria de Gobierno, Iogró que la inmigración hacia Venezuela tuviera resultados muy superiores en tér- minos demográficos con respecto a periodos anteriores que coincidió en el ámbito interno con un mayor ingreso fiscal por parte del Estado venezolano contando con mayores recursos para impulsar el proceso de captación y ayuda a la población migrante (Torrealba et al, 1983).

En 1948, a once años de la creación de la primera ley migratoria se empezó a discutir una nueva Ley de Migración, sin embargo no alcanzó a ser aprobada por el golpe de Estado ocurrido en noviembre de ese año ${ }^{20}$. Durante el período de 1945 a 1948 de la Junta Revolucionaria de Gobierno, conocido también como el "trienio adeco", se generó una política inmigratoria, selectiva, pero favorable al ingreso de extranjeros, "Ios mensajes presidenciales de la Junta dan cuenta de los resultados de esta política al reseñar, entre 1945 y 1947, el ingreso de 17.000 inmigrantes mediante gestión oficial y 25.000 extranjeros llegados al país por espontanea decisión. En 1948 fue registrado el ingreso de 11.307 inmigrantes y la incorporación de Venezuela a la Organización Internacional de Refugiados como vía para atraer mayores flujos de población europea" Torrealba et al (1983: 378).

A pesar de los cambios políticos internos, la política migratoria iniciada en el año 1936 no tuvo cambios significativos hasta el año 1949, siguió a cargo del Estado por medio de la Comisión Nacional de Inmigración, y continuó el sistema de colonias entre otras iniciativas.

20. En Noviembre de 1948 se realiza un golpe de Estado en el que participaron civiles y militares contra el gobierno de Rómulo Gallegos, del partido Acción Democrática con lo cual se daba fin al período conocido como el trienio adeco. Una vez derrocado se instaló una Junta Militar presidida por Carlos Delgado Chalbaoud. 


\subsection{La política de puertas abiertas 1948-1963}

Con el golpe de Estado ocurrido en noviembre de 1948 y la posterior conformación de una Junta Militar se da inicio a una nueva etapa política en Venezuela de cambios institucionales y administrativos, entre los cambios a destacar se encuentra la política migratoria.

Una de las primeras medidas fue eliminar el Instituto Técnico de Inmigración y Colonización (ITIC), creándose en el año 1949 el Instituto Agrario Nacional (IAN) adscrito al Ministerio de Agricultura y Cría. Entre sus funciones principales destaca, controlar y hacer seguimiento de la inmigración dedicada a actividades agrícolas bajo el sistema de colonias que ya venía en funcionamiento. Durante este período no se creó una ley específica en materia migratoria, tampoco normas o reglamentos. Lo migratorio que desde las primeras iniciativas gubernamentales de 1832 estuvo vinculado al desarrollo del agro, sin perder su propia institucionalidad, a partir del año 1949 su institucionalidad quedo subsumida dentro de la cartera de Estado de Agricultura y Cría.

Otro de los cambios introducidos en este período fue el promover la visa de transeúnte en detrimento de las iniciativas inmigratorias de colonización. "En 1946, el $43,1 \%$ de las visas otorgadas correspondían a inmigrantes y el $13,7 \%$ a transeúntes; en 1958 estos valores se habían invertido y solo hubo un $12 \%$ de visas de inmigrante, mientras que las visas de transeúnte ascendieron a un 63,2\%" (Torralba et al, 1983: 379). Con estas medidas se reorientaban las formas de ingreso al país en dos vertientes, por una parte se daban facilidades extraordinarias a la inmigración por medio de las políticas de puertas abiertas, esta vez dirigida no solo a agricultores, sino a un sinfín de profesiones y oficios; y por otra parte, se reducía la práctica ya tradicional de fomentar programas de inmigración con asistencia y protección al inmigrante. No obstante, si bien el gobierno asumía teóricamente los compromisos con aquellas personas que llegaban al país con visa de inmigrante, los compromisos ante los que tenían visa de transeúntes eran mínimos (Rey, 2011: 117)

Durante esta etapa se aplicaron iniciativas para procurar la adaptación de los migrantes a la sociedad venezolana como la refacción y reacondicionamiento de los centros de recepción; convenios con el Instituto Nacional de Nutrición para la alimentación de los migrantes en esos centros; asistencia jurídica; cursos de castellano, geografía e historia de Venezuela impartidos en la Universidad Central para los inmigrantes. Igualmente se creó la guía del inmigrante denominada "Venezuela. Informaciones útiles para inmigrantes".

En 1952, con la asunción a la presidencia del General Marco Pérez Jiménez y en el marco del "Nuevo Ideal Nacional"21, en conjunción con los excedentes de ingresos petroleros fruto del aumento de la producción, entrega de concesiones internacionales y factores geopolíticos que aumentaron los precios, se inició un agresivo proceso de inversión y desarrollo entre las

21. Es el nombre que recibió el programa político y doctrinario del gobierno de Marco Pérez Jiménez concretaba sus proyectos de grandeza nacional, apoyado en un aumento considerable de los ingresos fiscales derivados del boom petrolero y otras circunstancias ocurridas en la economía mundial. El Estado se convirtió en un gran inversor mediante la constitución de grandes complejos económicos, como el de Petroquímica y el de la Siderúrgica. 
que destacaba la modificación del medio físico y obras públicas (carreteras, autopistas, puertos, aeropuertos, instalaciones educativas, turísticas, hospitalarias, sindicales, habitacionales, industrias básicas, agroindustria, electrificación e instalaciones del ámbito militar).

El boom económico, la política de inversión y transformación del medio físico y la política migratoria de puertas abiertas contribuyó al desarrollo del sector comercial, financiero y de servicios lo que propició un clima favorable de empleo. La economía venezolana durante esos años, se orientó a la consolidación de la industria petrolera y a la expansión de la economía urbana, además de iniciar un proceso de industrialización basado en la sustitución de importaciones alrededor de las principales ciudades del país que generó un proceso de migración interna (Torralba et al, 1983: 380).

Destaca la instrucción que el General Pérez Jiménez le dio en el año 1952 a su Director de Inmigración: "Abra usted las puertas de la República a todo europeo que reúna las condiciones convenientes a su juicio" (Troconis, 1986: 275). En materia migratoria se desarrolla una política de "puertas abiertas" que contrasta con la "selectividad" del período anterior. Esta política fue especialmente difundida en los consulados de Italia, España y Portugal teniendo como resultado el aumento de inmigrantes de estos países. En el momento que se adopta esta política de puertas abiertas Venezuela ya contaba con más de cien años de experiencias en iniciativas que fomentaran, promovieran y protegieran la inmigración, con una fuerte tradición de políticas migratorias aperturistas.

En esta etapa, el perfil del inmigrante y los requisitos para el ingreso en Venezuela eran generales y flexibles: "solo se necesitaba ser menor de 35 años, no tener antecedentes penales y poseer un certificado de buena salud, no estaban previstas las exigencias relacionadas con determinados oficios, como se había hecho con anterioridad, ni respecto a cierto tipo de preparación profesional o técnica; tampoco estaba la inmigración sujeta a control y supervisión del Estado con el propósito deliberado de favorecer determinada actividad productiva, como lo había sido en tiempos del ITIC"(Quintero, 2017: 17). La mayor parte de los migrantes fueron europeos principalmente italianos, españoles y portugueses y en menor número alemanes, polacos, rusos y europeos orientales Dentro de las actividades desempeñadas estaban la construcción, el comercio, especialmente panaderías, restaurantes, cafeterías, siembras y obras públicas. (Ramos, 2010: 96 y 98)

A decir de Froilán Ramos, el Estado venezolano propició siempre la inmigración europea exclusivamente "proyectó la entrada a la nación de población de origen canario, italiano, portugués y español principalmente y luego del resto de Europa. Esto es lógico, debido a que la población venezolana es fruto de un proceso de un profundo proceso de mestizaje entre europeos y aborígenes, además un porcentaje importante de la población de Venezuela, superior al 30\% es de origen europeo..." (2010: 95).

Revisando la data del Ministerio de Agricultura y Cría a través de Catalina Banko podemos ver que "en la medida en que ya no había restricciones para la inmigración, se incrementó de modo sustantivo el ingreso de españoles, principalmente los procedentes de Canarias y Galicia (...) tal fue el grado de interés que despertaba 
Venezuela que en 1952, aparte de la misión de inmigración que se mantenía en Madrid, el gobierno venezolano decidió establecer otra oficina en Santa Cruz de Tenerife, para facilitar las gestiones consulares a los habitantes de las Islas Canarias (2019:129 y 130).

En el censo del año 1950 se señala que la comunidad española en Venezuela era de 37.887, personas la segunda en importancia después de la comunidad italiana. Álvarez y Ruíz citados por Ramos, señalan "...en 1946 ingresaron al país 5.000 europeos, 11.000 en 1947 y más de 20.000 en 1948. Para la década de 1950, el número de inmigrantes aumentó progresivamente, siendo el grupo más importante el de los españoles que ascendió a 200.000 entre 1951 y 1958. Estas corrientes venían en su mayoría de las Islas Canarias, las cuales representaban para 1958 alrededor del 13\% del total de inmigrantes del país..." (Ramos: 2010, pág. 98). Con todos estos antecedentes, Venezuela el 14 de febrero del año 1952 comenzó a formar parte del recién creado Comité Intergubernamental para las Migraciones Europeas (CIME)22.

En 1953 los delegados de los 24 países que conformaban el CIME aprobaron el plan de operaciones de 1954 que contemplaba llevar 117.600 europeos a países de ultramar. Dentro de dicho plan se contemplaba la emigración de 45.400 italianos $^{23}$,

22. El CIME se creó en Bruselas en el año 1951 en una conferencia convocada por el gobierno de Bélgica con el fin de solucionar a través de la migración los problemas de población y de refugio de los países europeos.

23. En 1954 se constituyó la Casa Italia un "Patronato Italo-venezolano" de asistencia a inmigrantes italianos. Se dijo allí que la colonia italiana en Venezuela, entre migrantes, residentes, transeúntes, turistas, etc. tenia 110.000 miem-
38.700 alemanes, 9.000 austriacos, 6.200 griegos, 4.400 holandeses y 3.500 refugiados de la zona de Shanghai en China. De este lote Venezuela recibiría 5.200 inmigrantes señalando que era una cifra moderada y que esperaba superar en el transcurso de ese año (Troconis, 1986: 281).

Con el ingreso de España al CIME se intensificaría la emigración hacia América y el gobierno venezolano estaba consciente que los españoles y canarios se adaptaban mejor que otros inmigrantes a las condiciones de vida de Venezuela. Por tal motivo el Vicepresidente del IAN de la época, Luis Alberto Rodríguez Azpúrua se dirigió a la ciudad de Madrid con el fin de contratar 30.000 españoles para las nuevas tareas de colonización agrícola que el gobierno se había fijado (Troconis, 1986: 283).

Durante la política de "puertas abiertas" 614.425 extranjeros recibieron cédula por primera vez, con lo cual se consagró en la práctica el derecho a la identificación para no nacionales, derecho que fue paulatinamente reconocido y mencionado por organismos multilaterales y gobiernos de las región a finales del siglo XX y comienzo del XXI. Si a los 614.425 extranjeros que obtuvieron identificación y regularización "...se considera los inmigrantes indocumentados, podría decirse que el saldo inmigratorio en Venezuela alcanzó las 800.000 personas. De la población inmigrante registrada, el $78 \%$ del total estaba compuesta por españoles, italianos y portugueses, clasificados respectivamente por orden numérico. Entre los españoles un tercio provenía de las Islas Canarias y otra cantidad similar de la región de Galicia" (Ramos, 2010: 98).

bros. Ver el Proceso de la Inmigración en Venezuela de Ermila Troconis. 
Al proceso de identificación de no nacionales hay que sumarle la Ley de Naturalización la cual fue promulgada en el año 1955 y que derogó la del año 1940. Dentro de sus principales objetivos estaba el de facilitar el proceso de otorgamiento de la nacionalidad venezolana a los extranjeros.

Al igual que etapas anteriores, la presente no solo fomentaba la inmigración, regularización e incluso identificación de las personas extranjeras que ingresaban a Venezuela, sino que también se contemplaban los derechos de acceder a la naturalización, es decir plenos derechos como ciudadano político de este Estado, esto es lo que se conoce en la literatura migratoria como el máximo grado de asimilación e integración a un nuevo país.

Un detalle que no es menor es el de las asociaciones de migrantes que se fueron conformando en Venezuela paulatinamente, "estas asociaciones actuaron de amortiguador del choque cultural a la llegada del individuo al posibilitar su incorporación-adaptación al nuevo país" Consuelo Naranjo citada en (Quinteros, 2017: 204). Representaron una especie de auto organización de parte de los migrantes como una forma de preservar su cultura y conformar redes de apoyo, así como también, para ayudar a nuevos migrantes. Se crearon entonces el Centro Portugués, el Centro Ítalo Venezolano y en el caso de la migración española se constituyeron: la Hermandad Gallega, el Centro Vasco, el Hogar Canario Venezolano, El Centro Asturiano y el Club Catalán entre otros ${ }^{24}$.

24. La migración española no constituyo un Centro Español único, a diferencia de los migrantes de otros países que se establecieron en Venezuela, esto tiene que ver más con las autodefiniciones e identidades culturales de cada región que componen España.
Vale la pena mencionar una iniciativa desarrollada en este período como fue la creación en Caracas de un Comité de Inmigración Infantil, el cual fue promovido por José Herrera Uslar, quien para la época era el representante de Venezuela en Noruega, Suecia y Dinamarca. Este comité tenia por fin organizar el viaje de adopción de al menos mil niños europeos que habían perdido a sus padres durante a guerra. Estos niños arribaban al país con pasaporte venezolano siendo adoptados por una familia venezolana.

En julio del año 1958 culmina formalmente la política de puertas abiertas ${ }^{25}$. Sin embargo el proceso de inmigración continuó. En el Censo del año 1961 se señalaba que el $68 \%$ de los extranjeros que hacía vida en Venezuela eran de origen europeo y de estos el mayor número provenía de España. Cabe destacar, que de acuerdo a estadísticas oficiales de España, "Venezuela fue el país iberoamericano que registró una inmigración española más numerosa posterior a la finalización de la segunda guerra mundial, especialmente a lo largo de los años cincuenta, presentando una tendencia creciente hasta 1957, fecha que dio la cifra más alta: 30.184 emigrantes: el 52\% de los dirigidos a América" (Quinteros, 2017:19).

El ritmo acelerado de inversión y construcción de obra pública se hicieron insostenibles y hacia finales de la década del 50 el desempleo aumentó por lo que "el régimen democrático que asumió el

25. Esto estuvo asociado al derrocamiento de la dictadura del General Marcos Pérez Jiménez en enero del 1958, el retorno a la democracia y la redacción de un nuevo texto constitucional. Los primeros años de esta nueva etapa política estuvieron signados por la negación de cualquier aspecto positivo que se hubiese dado en el régimen anterior, así como la revisión y paralización de obras y políticas emblemáticas. 
poder en 1958 buscó frenar el desempleo mediante el cierre drástico de la inmigración. A partir de ese momento los flujos migratorios empezaron a declinar y la etapa de puertas abiertas culminaba con saldo negativo" (Torralba et al, 1983: 380) en el año 1960 y 1961.

Al momento del derrocamiento del General Marcos Pérez Jiménez había en Venezuela un total de 526.625 extranjeros $^{26}$, de los cuales el $64,11 \%$ se encontraban en el Distrito Federal. A partir del año 1960 el saldo inmigratorio fue decreciendo consecutivamente, por varios motivos, uno de ellos la progresiva recuperación de las economías europeas de los países de origen de los migrantes, y en segundo lugar la desaceleración del modelo de expansión venezolano, con dificultades en la variable empleo, "la desocupación de quienes hasta entonces habían sido trabajadores, influyo también en que el nuevo gobierno restringiera la aceptación de inmigrantes, que solo venían a aumentar las filas de los desempleados" (Troconis, 1986: 293).

Durante la década del 60 al 70 se produce una drástica disminución de inmigrantes a Venezuela, con la excepción de portugueses y colombianos. Durante estos años se creó el Departamento de Migración Selectiva dentro de la Dirección de Economía y Empleo del Ministerio del Trabajo y en el año de 1966 se aprobó la Ley de Inmigraciones y Colonización que mantuvo el texto de la Ley de 1936, salvo los criterios raciales que fueron eliminados.

Otro aspecto importante a la hora de hacer análisis de políticas públicas migratorias es en lo referido a la seguridad social, entendiendo esta como "la protección que la sociedad proporciona a sus miem-

26. Ver: El Proceso de la Inmigración de Ermila Troconis, página 286. bros mediante una serie de medidas públicas contra las privaciones económicas y sociales..." (CIESS, 2010: 50). El vínculo entre seguridad social y migración reviste de gran importancia puesto que los migrantes generalmente se encuentran dentro de los sectores más vulnerables, en especial los trabajadores migrantes.

España y Venezuela suscribieron en el año 1988 el Convenio Bilateral de Seguridad Social, el cual se aplica a los nacionales de ambas partes así como a los miembros de sus familias que tengan derecho a las prestaciones según la legislación de cada parte, aplicable también a los refugiados y apátridas que residan en algunos de los dos países $^{27}$. Específicamente este convenio rige lo concerniente a casos de invalidez, jubilación, muerte y supervivencia, accidentes de trabajo y enfermedad profesional, sobrevivientes y asignación por muerte.

Podemos decir que con la suscripción de este acuerdo en materia de seguridad social se cierra el círculo de las políticas públicas inmigratorias que comenzaron con iniciativas de acogida, recepción, posteriormente integración, e identificación llegando a sistemas de protección y de seguridad social.

\section{Migraciones Latinoamericanas del Siglo XX}

En la década de los 70 comienza una nueva ola migratoria de importantes magnitudes en Venezuela, caracterizada por

27. Este Convenio está en consonancia con los postulados de la OIT con respecto a la protección de los trabajadores migrantes, de alguna manera se anticipa a lo que la OIT en el 2006 denomino los pisos de seguridad social y la trasnferibilidad de los derechos de seguridad social. 
una fuerte bonanza petrolera en vista del alza de los precios petroleros y el contexto además de la nacionalización de la industria, esta época es conocida popularmente como la Venezuela Saudita.

Nuevamente la combinación de hechos exógenos y endógenos fue clave en una nueva oleada migratoria. En 1973 la guerra del Yom Kipur, el bloqueo árabe a las economías occidentales y el aumento del gasto público llevado a cabo por el gobierno de Carlos Andrés Pérez generaron condiciones de empleo y de atracción de inmigrantes, esta vez de América Latina. A partir del año 73-74, "gracias al boom petrolero, y con la caída de la democracia, en prácticamente, toda América Latina, el saldo migratorio aumentó. Venezuela, junto con México, se convirtió en el refugio político de muchos latinoamericanos, o en su nueva oportunidad, la esperanza frente a la pobreza y represión de sus países de origen" (Ramos, 2010:99).

Llegaron a Venezuela colombianos, peruanos, ecuatorianos, bolivianos, dominicanos; fundamentalmente por dificultades económicas en sus países; y por otro lado chilenos, argentinos y uruguayos que huían de la persecución política de los gobiernos militares del cono sur. La población más numerosa de todas estas siempre fue la colombiana, que desde inicios de la década del 70 fue incrementando su presencia en Venezuela por los fuertes conflictos políticos y sociales que afrontaban.

Si en el año 1961 los españoles e italianos representaban el $53 \%$ de los extranjeros residentes en Venezuela, para el año 1971, apenas una década después, representaban menos del 40\%. Troconis refleja datos de José Eliseo López con respecto al incremento en ese mismo período de la migración colombiana "pasa de 19 a más de 30\%, lo que significa que de cada 100 extranjeros, 30 son colombianos" (1986:290), solo tomando en cuanta cifras de migración regular, pues estima la autora que el número de indocumentados puede ser de hasta cuatro veces más. No obstante, aún para el año 1976 los españoles representaban la primera comunidad de migrantes con el $27,5 \%$, seguido de los italianos con el $22,8 \%$ y ya en tercer lugar aparecían los colombianos con el 16,7\%.

En el año 1976 se pone en marcha el "V Plan de la Nación"28" en donde el gobierno definió las áreas prioritarias para el desarrollo económico como por ejemplo petróleo, petroquímica, siderúrgica, electrificación, los cuales para poder ser ejecutados requerían de mano de obra extranjera cualificada que supliera las demandas nacionales. En el mismo año el gobierno nacional creo el "Programa de Recursos Humanos" adscrito a la Oficina de Coordinación y Planificación de la Presidencia de la República (CORDIPLAN) e igualmente constituyó el "Comité Tripartito de Inmigración Selectiva", el cual sería el ente responsable del estudio y aprobación del personal extranjero calificado.

Para inicios del año 1976, había un total de 1.053.834 extranjeros registrados en Venezuela ${ }^{29}$, número que podía ser sensiblemente mayor por las personas indocumentadas o no regularizadas para ese momento. Al cruzar ese dato con el total de la población de Venezuela para el cierre del año 1975, la cual era de 13.189.50930

28. Plan Nacional de Desarrollo para el período 1976-1980.

29.Ver El Proceso de la Inmigración de Ermila Troconis, página 291.

30. Disponible en: https://datosmacro. expansion.com/demografia/poblacion/ venezuela?anio $=1976$ 
habitantes podemos ver que para 1976 el número de extranjeros regulares representaba el $8 \%$ del total del país.

Un tema que se refleja en la literatura y da cuenta de la preocupación de diversos sectores de la sociedad en aquel momento, era con la migración clandestina o la gran cantidad de indocumentados, en su gran mayoría provenientes de Colombia, a través de los "caminos verdes" propios de una extensa y porosa frontera entre Venezuela y Colombia, que hacía difícil precisar el número y magnitud de los migrantes colombianos. Por lo cual en 1980 durante el gobierno de Luis Herrera Campins, se realizó una Matricula General de Extranjeros con el objetivo de regularizar la presencia de los extranjeros que decidieron tomar a Venezuela como destino.

Según datos de la Dirección General de Identificación y Extranjería, para el año $1981^{31}$ existía un total de 1.365 .737 extranjeros cedulados en Venezuela procedentes de treinta y cuatro países del mundo, de los cuales 348.511 son colombianos, 276. 757 son españoles, 210.588 italianos, 137.084 portugueses como los países con mayor número de habitantes en Venezuela, destacando que no están contabilizados aquellos extranjeros que a través de la ley de naturalización hayan adoptado la nacionalidad y ser venezolano de plenos derechos o incuso algunos en situación irregular. Para ese mismo año, se registraban 19.320 argentinos y 27.618 chilenos.

En el año 1983 ocurre el llamado "viernes negro", que fue una de las devaluaciones más importantes del bolívar frente al dólar estadounidense, el tipo de cambio paso de estar a 4,30Bs por dólar, cambio que

31.Ver El Proceso de la Inmigración de Ermila Troconis, página 295-299. permaneció así desde el final de la segunda guerra mundial, a 7,50Bs. por dólar. Este hecho junto con la imposición de un control de cambio, inflación y problemas para el pago de la deuda externa determinaron la situación económica de Venezuela por varios años. Momento que coincide con la vuelta a la democracia y estabilidad política de varios países de la región, en especial los del Cono Sur, por lo que muchos migrantes retornaron a sus países de origen.

A finales de los 80 y principios de los 90 se produjeron dos acciones que pueden citarse como continuidad de prácticas de acogida y recepción por parte del Estado venezolano sin distingo de razones políticas. El primero de ellos ocurre en el año 1989 luego de conversaciones entre los Presidentes Carlos Andrés Pérez de Venezuela y Felipe González de España, Venezuela otorga asilo a once ciudadanos vascos, que posteriormente fueron catorce, vinculados al proceso independentista y que fueron deportados previamente por el gobierno español. Este gesto que fue agradecido por las autoridades españolas puesto que en el marco de la tensión interna por el conflicto separatista, no habían países dispuestos a asilar a estos ciudadanos vascos. De igual manera el Presidente Pérez tuvo un rol protagónico en convencer a Joaquín Balaguer, por entonces Presidente dominicano, de no extraditar a España a cinco ciudadanos vascos, vinculados a la lucha separatista, que vivían en la isla caribeña.

En segundo lugar, destaca los acuerdos alcanzados entre el exilio cubano y el gobierno de la isla para el arribo a Venezuela de un conjunto de presos políticos con largas condenas, "Eduardo García Moure, entonces Secretario General de la Confederación Latinoamericana de Trabajado- 
res y promotor y participante en el diálogo para llegar a este acuerdo, indica que el número exacto de familias cubanas que arribaron a Venezuela fue de 1003" (Rey, 2011: 141).

Finalmente, ya en el siglo XXI, el nuevo texto constitucional, aprobado por referéndum popular el 15 de diciembre de 1999, en su artículo Nº 33 establece facilidades de naturalización, en cuanto al tiempo mínimo de residencia en el país, a los inmigrantes de España, Italia, Portugal así como países latinoamericanos y del Caribe. En el año 2004 se aprueba la Ley de Extranjería y Migración, una actualización que estaba pendiente desde la entrada en vigencia en 1999 de la nueva Constitución Nacional. En dicha ley se estipula en el artículo $N^{\circ} 13$ que los extranjeros que se encuentren en la república tendrán los mismos derechos que los nacionales sin más limitaciones que las estipuladas en la Constitución. Igualmente en el artículo $\mathrm{N}^{\circ} 2$ se menciona que los efectos de la ley se aplicaran a aquellos extranjeros y extranjeras independientemente de su situación, es decir borrando aquellas barreras entre documentados e indocumentados.

En ese mismo año 2004, bajo el gobierno del Presidente Hugo Chávez a través del Decreto N².823 dispuso la realización de un "Plan de Regularización y Naturalización de Extranjeros" para pagar lo que el gobierno describió como la "Deuda histórica de Venezuela con los inmigrantes", por el cual se nacionalizaron 273 mil extranjeros en el lapso de un año ${ }^{32}$, de los cuales 186 mil serían de habitantes colombianos.

Según cifras del año 2010 de la Comisión Económica para América Latina y el Cari-

32. Ver: https://www.eltiempo.com/archivo/documento/MAM-1642362 be (CEPAL), Venezuela es el segundo país más receptor de todo el continente Americano, separado por un estrecho margen de Argentina quien ocupa el primer lugar.

\section{Conclusiones}

El análisis y revisión de las políticas públicas migratorias de Venezuela, da cuenta que de manera muy temprana, incluso antes de constituirse como república, el fomento a la inmigración estuvo vinculado al reconocimiento político de la nueva nación, posteriormente al repoblamiento del territorio nacional y el desarrollo del agro. Si bien esto puede ser tomado como un uso instrumental de la migración en dependencia de los intereses que el Estado venezolano o los distintos gobiernos de turno tuvieran, cada ciclo político definió legislación e institucionalidad migratoria, estableció estrategias y asignó recursos públicos para dicho tema, estableció actores intervinientes e incluso definió el perfil migratorio de interés (población objetivo), elementos todos que dan forma a una política pública inmigratoria.

A pesar de los cambios de gobierno, de civiles a militares y nuevamente civiles, sea que estos hayan tenido una legitimidad democrática en el voto o incluso fueran producto de un golpe de Estado, fueran más proteccionistas o aperturistas, se puede concluir que las políticas de fomento a la inmigración fueron una política de Estado, que estuvieron presentes de manera transversal en todos estos gobiernos, en algunos casos incluso siendo parte del plan programático de gobierno o de plan nacional de desarrollo. El auge de todo este sostenido esfuerzo contabiliza más de ciento cincuenta años. 
Esta política de fomento a la inmigración extendida en el tiempo, estuvo acompañada de aspectos como la exoneración de impuestos, exoneración del servicio militar, la articulación consular en el exterior para la atracción de migrantes, el derecho a la identificación a través de la cédula de identidad, la entrega de tierras baldías a los migrantes, integración social y económica, el acceso a la naturalización de los migrantes, acceso y cobertura a sistemas de seguridad social, entre otros. Lo cual representaba un tratamiento holístico del tema migratorio y para la época fueron en algunos casos innovaciones en el campo del derecho a la migración que puso a Venezuela a la vanguardia de estos temas a nivel mundial.

En la primera parte del siglo XX existieron planteamientos retrógrados de política migratoria basados en el componente racial o étnico (blanqueamiento) de la migración y su incidencia en la conformación de la sociedad venezolana, que fueron desmantelados por los gobiernos democráticos quienes pusieron especial atención en el carácter mixto (inmigrantes y venezolanos) de los proyectos desarrollados como formas de fomentar la integración.

Hay un nexo muy claro entre el fomento de la inmigración, incluso masiva, y el poblamiento y desarrollo del agro como eje central de la economía por algo más de setenta años, luego progresivamente la inmigración estuvo vinculada a la industria petrolera la cual había pasado a ser el epicentro de la economía venezolana. Esto no solo con la incorporación de personas a las actividades propiamente de la industria, sino en el resto de las actividades de la economía en especial la de la construcción de obras a partir del boom petrolero.

Aunque el Sistema Universal de Derechos Humanos que conocemos en la actuali- dad, fue construido a partir del año 1945 con la creación de la Organización de las Naciones Unidas (ONU) luego de la culminación de la segunda guerra mundial, se evidencian en el caso venezolano prácticas que representan antecedentes importantes en el reconocimiento temprano del derecho a migrar, de la reunificación familiar, al refugio, a la integración social e incluso políticas de retorno a sus países de origen, con las iniciativas gubernamentales puestas en marcha a partir de 1830 en adelante por los distintos gobiernos de turno de Venezuela.

Por lo lazos históricos-culturales la migración española fue de las más importante dentro de las migraciones europeas que se asentaron en Venezuela, aún hoy Venezuela (junto con Argentina y Francia) está dentro de los tres países del Mundo con mayor población española fuera de España. Mención aparte merece dentro de la migración española la proveniente de las Islas Canarias, migración que se difuminó a lo largo y ancho del territorio nacional ${ }^{33}$ y que no cesó en ningún momento desde antes de la disolución de la gran Colombia en 1830 y que perduró de manera sostenida por lo menos hasta la década de los ochenta del siglo XX.

La conformación de la sociedad venezolana a partir de múltiples intercambios cul-

33. Se tiene referencia de la conformación y funcionamiento de al menos 51 asociaciones de canarios en por los menos 17 de los 24 estados que conforman a Venezuela. De igual manera el Gobierno de la Comunidad Autónoma de Canarias en 1996 creo una oficina de representación del Gobierno de Canarias en Venezuela que depende de la Vice Consejería de Emigración, oficina a través de la cual los migrantes canarios pueden realizar múltiples trámites jurídicos, legales, de estudio, pensiones, ayudas, localización de familiares entre otros. 
turales, políticos, sociales, económicos, gastronómicos, de costumbres y tradiciones con las distintas oleadas de migrantes conformaron una sociedad multidiversa, con niveles de tolerancia e integración, donde el "otro" independientemente de su lugar de origen, su credo político o religión, no era percibido como un "extraño" o "amenaza" sino que formaba parte plena de la sociedad en su diversidad. Este proceso cultural acompañado de bonanza petrolera sostenida en el tiempo y de la universalidad de la educación configuró a la sociedad venezolana como una sociedad cosmopolita.

\section{Bibliografía}

Alvarez de Flores, Raquel (2007). "Evolución Histórica de las migraciones en Venezuela. Breve recuento". En Revista Aldea Mundo, Vol 11, № 22. Universidad de los Andes. Táchira, Venezuela.

Arambulo, Angelica (2016). "La política inmigratoria gomecista: positivimo y exclusión (1909-1945)". Centro de Estudios socio-históricos y culturales. Universidad Nacional Experimental Rafael María Baralt (UNERMB). Cabimas, Venezuela.

Arango, Joaquín (2003). "La explicación teórica de las migraciones: luz y sombra". En Revista Migración y Desarrollo, $N^{\circ} 1$, Octubre. Red Internacional de Migración y Desarrollo, Zacatecas, México.

Banko, Catalina (2019). "La inmigración española en Venezuela: una experiencia de esfuerzo y trabajo productivo". En Revista Espacio Abierto, Cuadernos Venezolanos de Sociología. Vol 28, No 1 . Universidad Central de Venezuela. Caracas.

Ceriani, Pablo. (2011). "Luces y sombras en la legislación migratoria latinoamericana". Revista Nueva Sociedad, N²33, mayo-junio.
Centro Interamericano de Estudios de Seguridad Social (2010). "Migración y seguridad social" Distrito Federal, México.

CEPAL (2010). "Tendencias y patrones de la migración latinoamericana y caribeña hacia 2010 y desafíos para una agenda regional". Serie Población y Desarrollo. Ediciones CEPAL, Santiago de Chile.

Constitución de la República Bolivariana de Venezuela 1999. Publicada en Gaceta Oficial N 5.453 del 24/03/2000.

Convenio de Seguridad Social entre España y Venezuela. Suscrito en Caracas el 12 de mayo de 1988, republicado en el Boletín Oficial del Estado (BOE) con correcciones de contenido en fecha 07/07/1990.

Gómez, Gaspar (1974). “Comité Intergubernamental para las Migraciones Europeas". En Revista de Instituciones Europeas, Vol.1, N² 2. España.

Ley de Extranjería y Migración N³7.944 de la República Bolivariana de Venezuela del 24/05/2004.

Martínez Pizarro, Jorge (2008). "Migración internacional en América Latina y el Caribe". Ediciones CEPAL, Santiago.

OIM. (2016). "Migración, Derechos Humanos y Política Migratoria”. Organización Internacional para la Migraciones y el Instituto de Políticas Públicas en Derechos Humanos del MERCOSUR.

Quintero, Inés (coord.) (2019). "Un lugar donde vivir y crear. Españoles en la Venezuela contemporánea". Embajada de España en Venezuela, Editorial Ariel. Caracas.

Ramos, Froilán (2010). “La Inmigración en la administración de Pérez Jiménez (1952-1958)" En Heurística, revista digital de historia de la educación, $N^{\circ} 13$. Universidad de los Andes, Venezuela.

Reglamento para la regularización y naturalización de los extranjeros y extranjeras que se encuentran en el territorio nacio- 
nal. Decreto 2.823 de fecha 03/02/2004.

Caracas.

Rey González, Juan Carlos (2011). "Huellas de la inmigración en Venezuela. Entre la historia general y la historia particular". Fundación Empresas Polar, Caracas.

Sartori, Giovanni (2001). “La sociedad Multiétnica: pluralismo, multiculturalismo y extranjeros". Editorial Taurus. Colombia. Sutcliffe, Bob (1998). "Nacido en otra parte: un ensayo sobre la migración internacional, el desarrollo y la equidad". Ediciones Hegoa. Bilbao, España

Torrealba, Suarez y Schloeter (1983). "Ciento cincuenta años de políticas inmigratorias en Venezuela". En Demografía y Economía, vol. 17, №3, Colegio de México. México D. F.

Troconis, Ermilia (1986). "El Proceso de la Inmigración en Venezuela". Biblioteca de la Academia Nacional de Historia. Caracas

Yepez, Isable (2007). "Las migraciones entre América Latina y Europa: una dimensión de las relaciones entre esas dos regiones". En Nuevas migraciones latinoamericanas a Europa, balances y desafíos. FLACSO-Ecuador. Quito. 